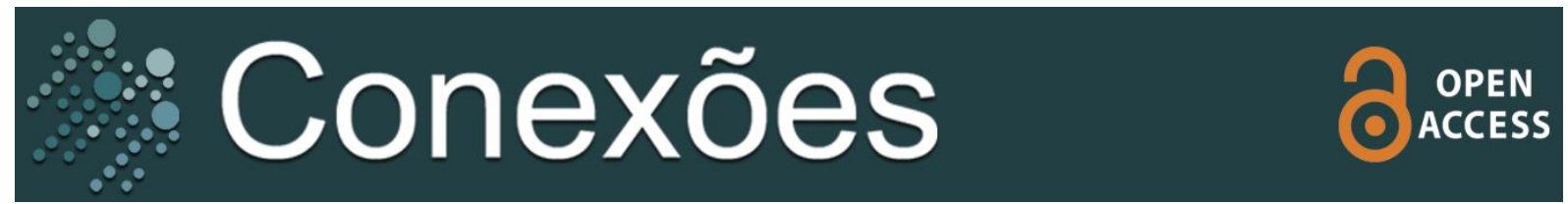

Apresentação

\title{
Os desafios da Educação Física em tempos de ataques à educação
}

Physical Education's challenges in times of attack on education

Los desafíos de la Educación Física en tiempos de ataques a la educación

\author{
Marcos Garcia Neira ${ }^{1}$ \\ Mario Luiz Ferrari Nunes ${ }^{2}$
}

\section{RESUMO}

Trata-se de um dossiê cujo objetivo é discutir a relação entre a Educação Física, escolas e políticas educacionais em jogo de forças que envolve o Estado, a sociedade civil e o mercado. Reúne artigos originais e relatos de experiência oriundos de diversas universidades brasileiras. Analisa a temática a partir de um olhar sobre a escola moderna que permite constatar que de tempos em tempos acirram-se as disputas para afirmar a função da educação física escolar na sociedade.

Palavras-chave: Educação Física. Educação. Escola. Neoliberalismo.

${ }^{1}$ Universidade de São Paulo, Faculdade de Educação, Departamento de Metodologia do Ensino e Educação Comparada, São Paulo - SP, Brasil.

2 Universidade Estadual de Campinas, Faculdade de Educação Física, Departamento de Educação Física e Humanidades, Campinas -SP, Brasil.

\section{Correspondência:}

Faculdade de Educação da USP, Avenida da Universidade, 308, Cidade Universitária, São Paulo SP, CEP 05508-040. Email: mgneira@usp.br 


\section{ABSTRACT}

This dossier discusses the relationship between Physical Education, schools and educational policies in a game of forces that involves the State, civil society and the market. It brings together original articles and experience reports from several Brazilian universities. It analyzes the theme from a look at the modern school that allows us to understand periodical disputes to assert the role of School Physical Education in society.

Keywords: Physical Education. Education. Neoliberalism.

\section{RESUMEN}

Se trata de un dossier cuyo objetivo es discutir la relación entre Educación Física, escuelas y políticas educativas en un juego de fuerzas que involucra al Estado, la sociedad civil y el mercado. Reúne artículos originales e informes de experiencias de varias universidades brasileñas. Analiza el tema desde una mirada a la escuela moderna que permite ver que periódicamente se intensifican las disputas para afirmar el papel de la educación física escolar en la sociedad.

Palabras Clave: Educación Física. Educación. Neoliberalismo. 


\section{Apresentação}

Um olhar genealógico sobre a escola moderna nos permite constatar que de tempos em tempos acirram-se as disputas para afirmar sua função, como tem que atuar e quem deve formar para compor o quadro social em cada momento histórico. Esse jogo de forças que envolve o Estado, a sociedade civil, a Igreja e o mercado também constitui a Educação Física.

Desde o final dos anos 1980, com a realização da Assembleia Constituinte, o debate acerca da escola no Brasil foi atravessado por interesses específicos e contraditórios. Se, de um lado, a Constituição definia o Estado de bem-estar-social como mote para o Brasil superar suas condições históricas de desigualdade, de outro, pairava a preocupação em inserir o país nos jogos político-econômicos da globalização. Por efeito, consolidaram-se políticas públicas que favoreceram a universalização da educação escolar, que permitiram o acesso e a permanência daqueles outrora dela excluídos - e, do mesmo modo, políticas alinhadas à racionalidade neoliberal, que criaram condições para a sua mercadização. 0 embate passou a ser organizar a educação como direito ou como mercadoria; instituir um modo solidário de vida ou o modo de vida dos indivíduos afeito à lógica neoliberal do mercado. Os resultados são conhecidos tanto no chão das escolas como nos locais de formação docente. Sem dúvida, assistimos a uma avalanche de práticas que fazem valer o ideário neoliberal e, simultaneamente, de resistência que promovem o que o pensador francês Michel Foucault (2008a) denominou de contra conduta: ações que indicam "não querer ser governado desse jeito"; que promovem outras formas de conduzir a vida.

O neoliberalismo é tomado como ideologia ou política econômica, mas não uma teoria. Há quem diga que se trata de um "espantalho", isto é, mais um termo genérico que nada explica, nem possui fundamento, apenas um grande vilão. Tal como acontece com o termo comunismo. Novamente, recorremos às análises de Foucault (2008a), para quem o neoliberalismo é uma arte de governo, ou seja, uma forma de operar o exercício de governo das populações e dos indivíduos, cuja especificidade é pautar-se por regras de economia máxima, apoiadas na noção de concorrência. Uma racionalidade que se alarga para todos os recônditos da vida, apagando a distinção entre o público e o privado. Por esse viés, entende-se que o neoliberalismo define as relações sociais e subjetiva os indivíduos, influenciando os modos de pensar e os comportamentos das pessoas.

Para a efetivação dessa forma de vida, a escola tornou-se peça central e, com ela, a formação docente. Afinal, a escola e os docentes atuam para formar as novas gerações que deverão consolidar as mudanças requeridas por uma nova ordem mundial, que é dada pelo mercado concorrencial. Não por menos, desde os anos 1990, estamos diante de políticas públicas e práticas culturais que impactam os processos de escolarização, os quais têm ensinado a atuar nesse jogo por meio do desenvolvimento de competências, interesses etc., mas de modo ainda e 
sempre estratificado. O que se percebe é que nesse jogo todos perdem econômica e existencialmente (VEIGA-NETO, 2000).

No Brasil, esse processo iniciou-se com o governo Collor de Melo (19901992), teve sequência com Itamar Franco (1992-1994), aprofundou-se nos dois mandatos de Fernando Henrique Cardoso (1995-2002) e se fortaleceu nos governos de Luiz Inácio Lula da Silva (2003-2010) e Dilma Rousseff (2011-2016). Apesar dos dois últimos efetivarem um governo com abertura para a maior participação da sociedade civil, consolidaram o neoliberalismo na educação ao permitir que organizações do terceiro setor influenciassem nas decisões do MEC e no estabelecimento de políticas públicas. Não foi à toa que o Instituto Ayrton Senna, o Movimento Todos pela Educação (grupo composto por mais 30 entidades ligadas ao setor financeiro), entre outros representantes de fração do empresariado nacional, como o Itaú Social, a Fundação Lemann, passaram a ditar as regras nas formas de organização e no trabalho pedagógico. O processo ganhou novos contornos após o golpe que instaurou o governo Michel Temer (2016- 2018). Desde então, o Estado adotou medidas mais ortodoxas da cartilha neoliberal. Apoiado por uma base política ultraconservadora, aprovou a Emenda Constitucional no 95, que congelou por 20 anos os recursos pertinentes às despesas primárias do gasto público, dentre eles a educação, além de promover a malfadada Reforma do Ensino Médio e a publicação de uma versão da Base Nacional Curricular Comum sem a participação do magistério ou da sociedade civil como um todo.

O Estado, ao assumir a lógica de organização do mercado, transformou o espaço público em terreno fértil para a disputa concorrencial de grupos diversos e interesses múltiplos. No caso da educação, a agenda política está dominada pela burguesia interna (BOITO JúNIOR, 2012). Trata-se de um grupo heterogêneo composto por segmentos da indústria, do sistema financeiro, de cadeias de varejo e outras áreas de negócio. Essa parcela da burguesia "ocupa uma posição intermediária entre a antiga burguesia nacional, passível de adotar práticas antiimperialistas, e a velha burguesia compradora, mera extensão do imperialismo no interior desses países" (p. 67). O que unifica grupos tão díspares é o compromisso com o capital financeiro internacional e a preocupação em preparar segmentos do mercado nacional para a concorrência externa. Para o sociólogo, esse é o motivo da proteção e participação do governo brasileiro em seus projetos. Gostemos ou não, esse setor da burguesia tem um projeto de educação para o país e usa de sua força econômica e política para efetivá-lo.

Essa ingerência do setor privado na educação nacional visa colocar o Brasil em boas condições de competitividade no mercado global, firmando novas formas de governança em redes políticas que favorecem as parcerias público-privadas. Para tanto, tudo que nela ocorre deve ser mensurado a fim de averiguar a "qualidade" de seus recursos humanos, visto que são eles que garantiriam o alcance desse objetivo. Assim como os termos crítica, cidadania e prática, 
presentes de forma ambígua nos documentos oficiais da Educação nacional com o intuito de legitimar os mesmos junto à diferentes grupos (LOPES, 2005; MACEDO, 2008; DIAS; LOPES, 2009), o termo "qualidade" também entra em disputa pela definição de seu significado (LOPES, 2014). Ele passa a ser algo quantificável, a ser convalidado por mecanismos de regulação internacionais, tais como o Pisa (Programa Internacional de Avaliação de Alunos), organizado pela OCDE (Organização para a Cooperação e Desenvolvimento Econômico) - entidade da qual o Brasil não é membro e há décadas busca alcançar níveis de desempenho econômico a fim de tornar-se.

Isso impacta diretamente a função da escola pública que por dar atenção à maioria da população, não favorece o alcance dos indicadores necessários à lógica competitiva da geoeconomia global. Como a maioria dos alunos não dispõe de condições econômicas e sociais para tanto, a velhas cantilenas se repetem, ecoando a ineficiência da escola, dos professores, do Estado, e legitimando a interferência de setores pseudo-vencedores, entenda-se, privados, nas políticas públicas educacionais.

Em relação ao Pisa, cabe destacar que se trata de um exame de avaliação de desempenho que mede o nível educacional de jovens de 15 anos por meio de provas de leitura, Matemática e Ciências. Mensura-se os conhecimentos e habilidades tomados como essenciais para a vida social e econômica, a fim de pautar políticas na formação dos jovens, homogeneizando modos de ser. Nessa avaliação, realizada a cada dois anos, o Brasil, que é convidado a comparecer, constantemente, ocupa os últimos lugares entre os mais de 70 países participantes. No entanto, ao se analisar os extratos das escolas representadas (municipal, estadual e federal), os alunos das escolas federais ocupam os primeiros lugares, o que colocaria o Brasil à frente de países membros da OCDE como EUA, Alemanha e Coréia do Sul. Como se sabe, esse dado não dispõe de visibilidade nas mídias. Ou seja, as escolas referência para a melhoria da educação pública não são as particulares, tampouco suas formas de gestão e práticas pedagógicas.

Se, de um lado, as particularidades do Brasil produzem ataques à escola pública por parte dos setores nela interessados, por outro, a ação do Estado se dá nessa direção porque no neoliberalismo, o ambiente deve ser dirigido e modelado pelos governos e pelo Estado, a fim de produzir a liberdade, que passa a ser também objeto de consumo. O Estado dirige e modela os cenários por meio de políticas públicas, estabelece as práticas e o modo como a instituição escolar executará tal tarefa.

Para asseverar nossa posição, cabe retomar algumas dessas políticas, como a avaliação em larga escala - presente em todos os segmentos da educação; políticas que definem diretrizes e programas curriculares comuns para todos os cursos, níveis, etapas e modalidades de ensino pautadas nas competências 
exigidas pelo mercado; políticas de financiamento e gestão consubstanciadas em resultados de eficiência, que também incidem sobre a prática docente e a produção acadêmica; métricas para a gestão desse financiamento, como o CustoAluno-Qualidade (CAQ) da Educação Básica; as políticas de bonificação docente vinculadas aos resultados nas avaliações de larga escala, entre outras.

Em relação às práticas escolares, tornou-se comum a secundarização do planejamento dos objetivos e da seleção dos conteúdos; a ênfase em variação de estratégias (criatividade) para colocar os conteúdos em ação; a multiplicação de processos de avaliação no cotidiano escolar, seja das aprendizagens alcançadas, seja dos professores, até mesmo dos serviços prestados; a insistência em metodologias ativas; o ranqueamento de pessoas e instituições; a terceirização de diversos serviços; a "invasão" de projetos e parcerias do terceiro setor com enorme poder de sedução junto aos professores e à comunidade escolar; o incentivo à determinada teorização pedagógica; a precarização da formação docente e a sua proletarização mediante tarefas que extrapolam sua jornada de trabalho; o discurso do "fazer a diferença" associado aos processos de inclusão/excludentes de sujeitos fora dos padrões normativos (NUNES; NEIRA, 2014) entre tantas.

Para Ball (2006), os efeitos de mercado nas reformas da educação são correlatos de uma psicologia social do auto-interesse. Com isso, aprende-se que os resultados da escola/empresa são mais importantes que quaisquer princípios que orientam a ética. Combina-se um rol de recompensas e incentivos que possibilitam estabelecer a concorrência entre os indivíduos como algo característico dos humanos, que tomam a si mesmo como referência, sujeitos auto-interessados. Para o sociólogo da educação inglês, as práticas e políticas neoliberais geram um ambiente moral, que ao tornar todos consumidores e produtores, colocam ambos em uma cultura dos interesses de si mesmo. 0 mercado enaltece a ética dos desejos e interesses individuais e, ao mesmo tempo, negligencia e rejeita qualquer ponto de vista comum. São essas formas de organização que visam tomar a educação escolar como braço do Estado a serviço do neoliberalismo no Brasil contemporâneo.

Se é evidente a presença da racionalidade neoliberal na educação, ela também está fortalecida diante das políticas do corpo, que não permitem à Educação Física rebelar-se contra esses acontecimentos. Se o neoliberalismo envolve a todos a fim de produzir modos de subjetivação empresarial e competitivo, a construção desse sujeito Eu S/A baseia-se em um estilo de vida ativo, que requer total submissão do corpo e da alma do sujeito-empresa para que atue de forma competitiva e com o máximo de eficiência nas diversas situações do cotidiano (NUNES; NEIRA, 2018a). A meta, inalcançável, diga-se, é a plenitude de si, para com isso autovalorizar-se. Não à toa, proliferam espaços para o exercício de práticas corporais em busca do condicionamento físico perfeito, do corpo saudável, além da mercadorização e consumo das mesmas (NUNES; NEIRA, 
2008b). Não por menos, segundo dados do portal e-MEC, o crescimento dos cursos de Educação Física no Brasil entre 2005 e 2015 ultrapassou 70\%. Além disso, o sujeito EU S/A deve assumir a responsabilidade por suas escolhas, tomando para si o risco do fracasso ou sucesso de suas empreitadas, o que implica a auto-superação. Colocam Dardot e Laval (2016), que na busca da alta performance, o empresário de si busca outras possibilidades de "asceses" a fim de melhorar o seu rendimento. Emergem os gurus do desempenho tais como os coachs e os personal, que aplicam técnicas para o cuidado de si, receitam atividades que vão desde o yoga até a programação neurolinguística, passando pela hipnose, palestras motivacionais e esportes de aventura. Para os autores, o que se busca é a autossuficiência, o maior domínio de si mesmo, logrando resultados positivos a fim de alçar padrões de excelência, tanto para o alcance de metas pessoais como para as relações interpessoais.

Da realização de megaeventos esportivos ao atual culto aos mitos dos esportes com seus corpos delineados, o ideal de alta performance também afeta a vida íntima, a vida sexual, que também passa a ser exposta em redes sociais diversas para efeitos de comparação. O objetivo é cingir performance ao prazer, compondo um sujeito que seja eficiente em qualquer situação e que viva no limite (DARDOT; LAVAL, 2016). Ser empresário de si é investir e fazer do seu corpo sua mídia, seu cartão de visitas. $O$ que se tem é a cruzada pela saúde e a remodelação do corpo, que é o ajuste dos sujeitos aos desafios e demandas destes tempos. Não é à toa que corpo e saúde ocupam o centro privilegiado da discussão acerca do atual princípio ético, político e estético no governo de si e dos outros divulgados pelo neoliberalismo (CÉSAR; DUARTE, 2009).

Sabemos que na Educação Física ocorreram continuidades e descontinuidades em relação aos seus modos de existência. Afirmamos sem titubear que, no contexto da crise (da modernidade, do Estado, da escola, da Educação Física) emergiu outra Educação Física, marcada com o adjetivo que passou a carregar: escolar.

Em que pese não concordarmos com o termo (por conta da sua gênese moderna se dar na escola, entendemos que outras formas de ser é que deveriam ser adjetivadas), o uso do adjetivo contribuiu para delimitar a produção do conhecimento às questões que envolvem a Educação Física na escola. Por ser escolar, aproximou-se das ciências da educação e das ciências humanas em geral. O debate, então, acalorou-se e vários aportes teóricos passaram a compor as suas análises, potencializando pesquisas, práticas pedagógicas e a ação política docente.

Se as questões da sua especificidade e legitimidade tomaram conta dos primeiros passos dessa "nova" Educação Física, hoje, legitimada no espaço escolar, outros temas tomam a cena, tensionando sua especificidade e incorporando outras demandas sociais decorrentes da presença de TODOS na 
escola (todas as raças, classes, religiões, corpos, etnias, sexualidades e outras formas de representação do sujeito ainda não catalogadas). O impacto desse processo nas ciências e na escola é evidente, pois tanto a produção científica quanto a sua presença em periódicos acadêmicos se expandiu.

$\mathrm{O}$ atual contexto se difere daquele do final do século $X X$ e do início deste. $A$ arte neoliberal de governo se tornou hegemônica e ondas de conservadorismo recrudesceram. Com isso, temas como competitividade, autoempresariamento e responsabilidade individual (o fazer a diferença) naturalizaram-se, do mesmo modo que a constante exigência de superação de metas e a disposição permanente para o trabalho, entre outras práticas,aumentaram a incidência de sofrimento psíquico dos docentes e discentes.

O quadro se agrava ainda mais diante da presença constante de forças neoconservadoras que ampliaram exponencialmente as formas autoritárias de ser e as produtoras de violência. Os processos de escolarização tornaram-se alvos de duplo ataque - econômico e moralista. O resultado tem sido a efetivação de um ambiente de incertezas para os docentes, quanto aos objetivos da sua função, e para os discentes, em relação as suas expectativas de futuro. Se a abertura da escola para TODOS permitiu a multiplicidade de formas de pensar a Educação Física, os embates anunciados colocam o professor à mercê de um conflito, pois Ihe é atribuída a responsabilidade pelos problemas da sociedade, sejam econômicos ou morais.

Esse quadro nos inquieta e, longe de nos imobilizar, nos movimenta; longe de nos abater, nos anima. Este dossiê tem a pretensão de potencializar a Educação Física que acontece nas escolas como estratégia de resistência aos ditames anunciados. O que vemos são possibilidades de enfrentamento do neoliberalismo e dos movimentos neoconservadores. São escritas de resistência e produção de contra condutas aos imperativos e massacres globais/locais que querem capturar a vida.

Marcio Cardoso Coelho, Daniel Teixeira Maldonado e Fabiano Bossle, no artigo Professor de Educação Física (escolar) intelectual transformador: resistências ao modelo gerencialista e neoconservador da educação de mercado discutem a potencialidade da prática educativa intelectual e transformadora em tempos de educação neoliberal e do avanço dos movimentos neoconservadores no território brasileiro. A partir da análise de duas experiências políticopedagógicas de Educação Física, uma em Porto Alegre, outra em São Paulo, defendem que um professor intelectual busca a transformação social, pensa em todas as suas ações educativas para fazer resistência ao sistema econômico, compreende que é apenas o trabalho coletivo que pode modificar a realidade injusta e assume a responsabilidade em organizar projetos educativos que dialogam com uma escola pública democrática. 
Fabiana Leifeld elabora um relato reflexivo em Educação Física escolar: práticas docentes aprisionadas nas grades curriculares. Diante das adversidades oriundas da obrigatoriedade em seguir referenciais curriculares oficiais, compartilha as angústias e os desafios educacionais enfrentados numa escola do interior paranaense e denuncia a visão neoliberal dissimulada nas grades curriculares. Mesmo diante das dificuldades experimentadas no ano pandêmico de 2020, a professora se viu impelida a seguir as propostas curriculares conteudistas, permeadas por um discurso de poder, o que não a impede de ponderar acerca do propósito autêntico da educação.

Luciene Ferreira da Silva em Educação e lazer: reflexões sobre o PNE e a BNCC à luz da pedagogia histórico-crítica, analisa os espaços políticos de atuação neste momento histórico, considerando as urgências decorrentes das mudanças na organização do trabalho, na economia e na política brasileiras. Explica que, por um lado, a educação dualista favorece a formação dos estudantes dos estratos privilegiados e, por outro, desfavorece a educação para e pelo lazer na escola e fora dela para os estudantes da classe trabalhadora. Considera que os trabalhadores não são educados para o lazer e nem para reivindicar a participação social em programas de lazer. Aponta o avanço das políticas neoliberais, com desestruturação do trabalho que impacta a sociedade como um todo. As metas e estratégias do PNE se perdem na BNCC, mas, segundo a autora, podem ser abordadas a partir da pedagogia histórico-crítica, corroborando o processo de transformação da organização social vigente, a fim de viabilizar a educação e o lazer de qualidade para a classe trabalhadora.

Fernando Lionel Quiroga, Beatriz Aparecida Paolucci, Kelly Ferreira Pires, Isaac de Lima Neves e Maycon Ornelas Almeida abordam temática atualíssima em Militarização da escola pública em Goiás: dilemas da Educação Física escolar em tempos de autoritarismo. Discutem o processo histórico que culminou na militarização de uma parte da rede pública goiana, baseada na transferência da gestão escolar à Polícia Militar. Os autores discutem o contexto da crise educacional brasileira como pano de fundo da militarização da escola pública e os dilemas que se impõem ao ensino da Educação Física Escolar nesse contexto. Consideram a militarização da escola pública como uma política oportunista que sob a aparência de restauro da autoridade e da ordem busca implementar políticas neoliberais, cabendo à Educação Física apresentar-se como forma de resistência, posicionamento e luta pelos valores democráticos.

Misma Lima Mariano, Jayme Felix Xavier Junior, Maria Larissy da Cruz Parente, João Gabriel Eugênio Araújo e Diego Luz Moura analisam as aulas que tematizaram as atividades circenses no artigo História de vida e formação continuada: análise de uma experiência de ensino sobre as atividades circenses.Para tanto, observaram o trabalho pedagógico, entrevistaram a professora responsável e convidaram os estudantes a responderem um questionário. Os autores destacam que a busca por uma 
formação profissional e aspectos da trajetória docente potencializam boas práticas no ensino da Educação Física.

Gislei José Scapin, Gabriel Vielmo Gomes e Maristela da Silva Souza chamam a atenção para Os atuais desafios para a organização do trabalho pedagógico na escola: uma discussão a partir dos estágios curriculares supervisionados em Educação Física. Partindo das experiências vivenciadas no estágio desenvolvido em uma escola pública do município de Santa Maria (RS), apresentam a proposta de trabalho e, por fim, pautam algumas discussões sobre os desafios para pensar/elaborar o trabalho pedagógico. Constatam como desafios a alocação das aulas de Educação Física no contraturno escolar e a esportivização das práticas pedagógicas, o que acaba por corroborar a desqualificação da área no contexto escolar.

Por último, apresentamos o artigo Aleturgia do currículo cultural na Educação Física: experiências pedagógicas potencializadoras de subjetividades não-fascistas, de Pedro Xavier Russo Bonetto e Rubens Antonio Gurgel Vieira. Com o objetivo de ampliar a concepção de fascismo, relacionando-o com propostas conservadoras e reacionárias do componente, dado que se baseiam na assimilação das diferenças e na apropriação humanística, além de se respaldar na crença da homogeneização das teorias psicobiológicas ou mesmo das metanarrativas críticas, adotaram o método filosófico para articular,com originalidade,a produção mais recente sobre o currículo cultural de Educação Física com o construto filosófico foucaultiano e deleuze-guattariano. Os autores indicam que a partir de sua aleturgia, a proposta pode ser uma alternativa de potencialização de subjetividades não-fascistas.

\section{REFERÊNCIAS}

BOITO JUNIOR, Armando. Governos Lula: a nova burguesia nacional no poder. In: BOITO JUNIOR, Armando; GALVÃO, Andrea (Org.). Política e classes sociais no Brasil dos anos 2000. São Paulo: Alameda, 2012. p. 67-103.

CÉSAR. Maria Rita; DUARTE, André. Governo dos corpos e escola contemporânea: pedagogia do fitness. Educação \& Realidade, Porto Alegre, v. 2, n. 34, p. 119-134, maio/ago. 2009.

DARDOT, Pierre; LAVAL, Christian. A nova razão do mundo: ensaios sobrea sociedade neoliberal. São Paulo: Boitempo, 2016.

DIAS, Rosanne Evangelista; LOPES, Alice Casimiro. Sentidos da prática nas políticas de currículo para formação de professores. Currículo sem Fronteiras, v. 9, n. 2, p. 79-99, jul./dez. 2009.

FOUCAULT, Michel. Segurança, território e população. São Paulo: Martins Fontes, 2008a.

FOUCAULT, Michel. O nascimento da biopolítica. São Paulo: Martins Fontes, 2008b. 
LOPES, Alice Casimiro. Parâmetros Curriculares para o Ensino Médio: quando a integração perde seu potencial crítico. In: LOPES, Aline; MACEDO, Elisabeth. (Orgs.). Disciplinas e integração curricular: história e políticas. Rio de Janeiro: DP\&A editora, 2002.

MACEDO, Elisabeth. Que queremos dizer com educação para a cidadania? In: LOPES, Alice et al. (Orgs.) Políticas Educativas e dinâmicas curriculares no Brasil e em Portugal. Petrópolis: DP et Alii; Rio de Janeiro: Faperj, 2008.

MATEUS, Danielle Santos; LOPES, Alice Casimiro. Sentidos de qualidade na política de currículo (2003-2012). Educação \& Realidade, Porto Alegre, v. 39, n. 2, p. 337-357, abr./jun. 2014.

NUNES, Mario Luiz Ferrari; NEIRA, Marcos Garcia. Processos de inclusão excludente presentes no Ensino Superior privado. Educação \& Realidade, Porto Alegre, v. 39, n. 04, p. 1209-1228, out./dez. 2014.

NUNES, Mario Luiz Ferrari; NEIRA, Marcos Garcia. EU S/A: a identidade desejada na formação inicial em Educação Física. Educação e Pesquisa, São Paulo, v. 44, e174633, 2018a.

NUNES, Mario Luiz Ferrari; NEIRA, Marcos Garcia. O currículo de licenciatura em educação física e a fabricação do sujeito-cliente. Revista Brasileira de Educação, v. 23, e230038, jul. 2018b.

VEIGA-NETO, Alfredo. Educação e governamentalidade neoliberal: novos dispositivos, novas subjetividades. In: PORTOCARRERO, Vera; CASTELO BRANCO, Guilherme. (Orgs.). Retratos de Foucault. Rio de Janeiro: Nau, 2000. p. 179-217.

A revista Conexões utiliza a Licença Internacional Creative Commons Atribuição 4.0, preservando assim, a integridade dos artigos em ambiente de acesso aberto.

A Revista Conexões é integrante do Portal de Periódicos Eletrônicos da Unicamp e associado/membro das seguintes instituições:
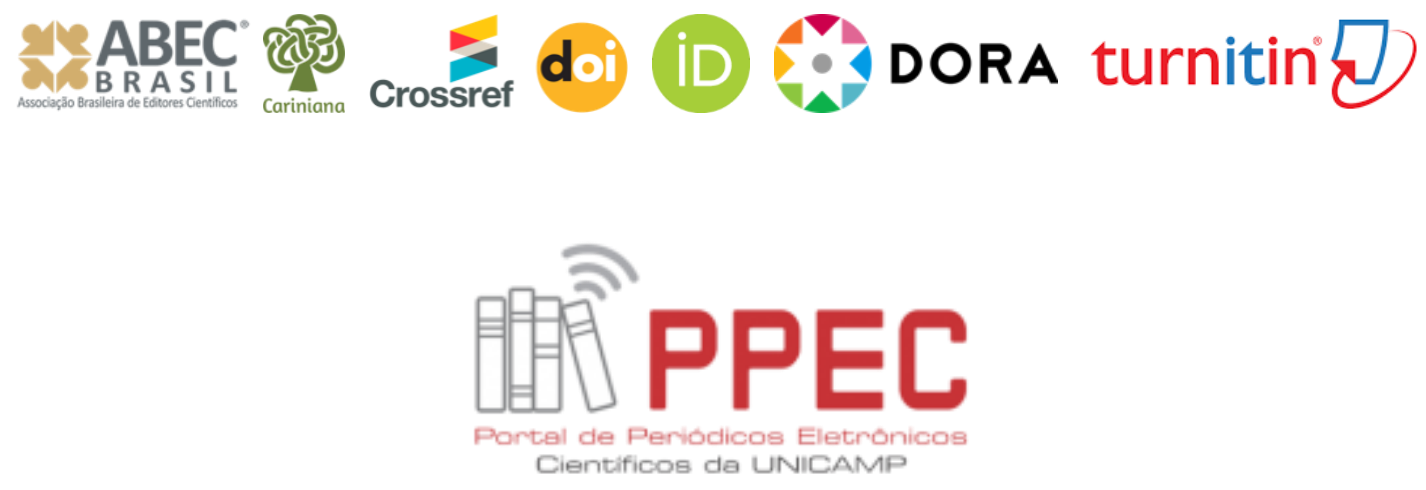